\title{
Como o trabalho precarizado na saúde afeta o modo de nascer: revisão integrativa sobre violência obstétrica
}

\author{
How precarious work conditions in health affect birth: an integrative review on obstetric \\ violence
}

\section{Cómo el trabajo precarizado en la salud afecta al modo de nacer: revisión integrativa sobre violencia obstétrica}

\section{Recebido: 10/09/2018 \\ Aprovado: 15/04/2019 \\ Publicado: 01/07/2019}

\author{
Maria Carolina Pádua Pinto Naques Faleiros ${ }^{1}$ \\ Nayara Hakime Dutra Oliveira ${ }^{2}$
}

0 presente estudo tem por objetivo realizar uma revisão integrativa da literatura, de artigos publicados na plataforma LILACS, e, baseando-se no método histórico dialético, estabelecer uma relação entre a precarização das relações trabalhistas na saúde e os altos índices de violência obstétrica sofrida pelas gestantes nas maternidades brasileiras. Foi feito um levantamento, realizado no período de junho a agosto de 2018, dos artigos publicados com o índice "violência obstétrica" e "trabalho precarizado", considerando o período de 2013 a 2017. Os resultados consideraram 14 artigos e apontaram que é possível estabelecer uma relação entre a precarização do trabalho e a prática da violência obstétrica, perpassando pelos campos da categoria do trabalho na concepção marxiana, da construção histórica do modelo atual de saúde no Brasil e das formas de apropriação dos profissionais da saúde no trabalho de parto e no corpo da mulher.

Descritores: Saúde da mulher; Violência contra a mulher; Parto humanizado; Obstetrícia.

This study aims to conduct an integrative literature review of articles included in the LILACS platform, and to, based on a dialectic-historical method, establish a relation between the precariousness of health work relations and the high rates of obstetric violence to which pregnant women are subjected in Brazilian maternity clinics. A survey was carried out from June to August 2018, including articles which had the indexes "obstetric violence" and "precarious employment", considering the period from 2013 to 2017. Os resultados consideraram 14 artigos e, apontaram que é possível estabelecer uma relação entre a precarização do trabalho e a prática da violência obstétrica, perpassando pelos campos da categoria trabalho na concepção marxiana, a construção histórica do modelo atual de saúde no Brasil e as formas de apropriação dos profissionais da saúde no trabalho de parto e no corpo da mulher.

Descriptors: Women's health; Violence against women; Humanizing delivery; Obstetrics.

El presente estudio tiene por objetivo realizar una revisión integral de la literatura de artículos publicados en la plataforma LILACS y, basada en el método histórico dialéctico, establecer una relación entre la precarización de las relaciones laborales en la salud, con los altos índices de violencia obstétrica sufrida por las gestantes en las maternidades brasileras. Fue hecho un levantamiento realizado en el periodo de junio a agosto de 2018, de los artículos publicados con el índice "violência obstétrica" y "trabalho precarizado", considerando el periodo de 2013 a 2017. Los resultados consideraron 14 artículos y apuntaron que es posible establecer una relación entre la precarización del trabajo y la práctica de la violencia obstétrica, permeando por los campos de la categoría trabajo en la concepción marxista, la construcción histórica del modelo actual de salud en Brasil y las formas de apropiación de los profesionales de la salud en el trabajo de parto y en el cuerpo de la mujer.

Descriptores: Salud de la mujer; Violencia contra la mujer; Parto humanizado; Obstetricia.

1. Advogada. Assistente Social. Mestranda do Programa de Pós-Graduação em Serviço Social da Universidade Estadual Paulista Júlio de Mesquita Filho (UNESP), Franca, SP, Brasil. ORCID: 0000-0001-7319-9610 E-mail: carolinadepadua@yahoo.com.br

2. Assistente Social. Mestre e Doutora em Serviço Social. Professor Assistente Doutor do Departamento de Serviço Social da UNESP, Franca, SP, Brasil. ORCID: 0000-0001-6505-4825

E-mail: nayarahakime@gmail.com 


\section{INTRODUÇÃO}

$\mathbf{P}$ ara se falar em violência obstétrica ${ }^{1}$ termo considerado novo - nos moldes propostos pelo presente estudo, faz-se necessário, antes, fazer algumas considerações acerca do modo de produção sobre o qual a sociedade está estruturada, para, posteriormente, compreender como ele afeta a vida das parturientes.

Considera-se aqui a categoria "trabalho" dentro dos limites da teoria marxiana, a ideia central de que os homens, para existir, devem transformar a natureza e, sempre que a transformam, se transformam, adquirem novos conhecimentos e habilidades ${ }^{2}$, ou ainda, o trabalho é um processo entre o homem e a Natureza, um processo no qual o homem, por sua própria ação, media, regula e controla seu metabolismo com a Natureza ${ }^{3}$.

0 que diferencia os homens dos animais (que também modificam a natureza, como as abelhas que há séculos constroem suas colmeias exatamente iguais) é que, antes de executar, o homem idealiza o trabalho que irá realizar3. Essa idealização pode ser chamada de prévia-ideação, que é uma resposta, entre outras possíveis, a uma necessidade concreta ${ }^{2}$. Essa idealização somente surge quando uma necessidade se torna aparente. Portanto, o homem, ao ter uma necessidade, usa sua inteligência, idealiza uma ação e, ao executá-la, modificando a natureza, modifica a sua vida e a dos que estão à sua volta, mudando toda a sociedade, sendo o homem um ser social.

0 homem dispõe de uma força de trabalho, física e mental. Ele realiza uma prévia idealização de sua ação e, posteriormente, a executa, valendo-se dessa força. A força de trabalho de cada indivíduo é a parte mais essencial do homem².

Por meio do trabalho, o homem exterioriza sua força, emprega seus atributos e se reconhece no produto que criou. 0 produto final adquire um valor de uso, pois sua criação foi motivada por uma necessidade anterior. 0 meio de produção surge quando o valor de uso entra novamente em um processo de trabalho.

0 processo de trabalho se modifica ao longo dos anos. Hoje, o que foi denominado trabalho abstrato (uma vez que trabalho concreto responde pelas qualidades físicas do objeto $^{3}$ se relaciona com o gasto indiferenciado de energia humana dispendida para a realização daquele trabalho (diferente do trabalho como categoria fundante do ser social). 0 homem, a partir do momento em que vende sua força de trabalho para sobreviver, passa a trabalhar para o sistema capitalista, produzindo mercadorias e gerando a maisvalia, para a autovalorização do capital ${ }^{2,3}$.

Uma vez que o trabalhador passa a trabalhar para seu empregador, a favor do capital (vendendo sua força de trabalho e gerando mais-valia), o empregador tentará a todo custo evitar desperdícios, otimizar o tempo e sugar do empregado o máximo possível de sua força de trabalho, porque quanto mais ele for explorado, mais lucro o empregador conseguirá.

Essa situação de exploração da mão de obra assalariada deixa o trabalhador na condição de subalternidade em relação ao empregador. Hoje a sociedade se encontra num estágio no qual, para sobreviver e suprir suas necessidades básicas, o cidadão não dispõe de outra alternativa senão vender sua força de trabalho em troca do salário, tornando o empregado, além de expropriado, alienado, ou seja, alheio ao que produz, sem se reconhecer no produto final'2.

As necessidades humanas podem ser divididas em necessidades básicas e necessidades intermediárias. As necessidades humanas básicas, como categorias objetivas e universais, que devem ser satisfeitas concomitantemente, são: saúde física e autonomia ${ }^{4}$. Nesse processo, as necessidades humanas do trabalhador deixam de ser consideradas.

0 trabalho assalariado/alienado exerce uma ação usurpadora sobre a autonomia do trabalhador, uma vez que o capital cria necessidades de mercado em detrimento das necessidades humanas.

Remetendo ao trabalho no âmbito da saúde, observa-se que os trabalhadores, nesse contexto, também vendem sua força de trabalho em troca de salário. Esses trabalhadores possuem sentimentos, expectativas, desejos, planos, e muitas vezes se encontram desmotivados pelo baixo salário e pela falta de reconhecimento, tendo que trabalhar em mais de um local devido às baixas remunerações 5 , o que desencadeia uma sobrecarga de trabalho, aliada à infraestrutura inapropriada, ao despreparo e à desmotivação 5 .

Do outro lado, estão as pacientes gestantes, internadas em um momento delicado da vida, que é dar à luz um filho. Nessa situação, as mulheres ficam carentes de atenção, necessitando de um gesto humano: um olhar, uma palavra, uma escuta atenta, um acolhimento, para que possam se fortalecer na sua própria humanidade 6 .

Destarte, nesse processo contraditório do trabalho, encontram-se inúmeros trabalhadores da saúde. Médicos, enfermeiros, técnicos de enfermagem, assistentes sociais, psicólogos, nutricionistas, entre outros possíveis, todos atuando e vivenciando as expressões do capital em seus cotidianos no atendimento direto às gestantes.

0 acompanhamento adequado por parte da equipe médica durante o trabalho de parto promove benefícios à evolução do parto natural que, por sua vez, traz benefícios à saúde da mãe 
e da criança. Porém, a violência obstétrica é real. Com as inúmeras pesquisas na área, chegou até mesmo a ser quantificada, conceituada e divulgada.

As entidades governamentais e a Organização Mundial da Saúde (OMS) a reconhecem e publicaram dossiês, orientações, cartilhas, na intenção de instruir tanto gestantes quanto equipes médicas, buscando evitar que a violência obstétrica aconteça. Porém, ela não tem diminuído com o passar dos $\operatorname{anos}^{5}$.

É inevitável refletir sobre as causas que levam à prática da violência obstétrica. Este estudo pretende traçar uma relação entre os profissionais (agentes da violência) e as gestantes (vítimas), perpassando as condições precárias de trabalho. Os profissionais da saúde, inseridos na lógica mercadológica do trabalho, cada vez mais expropriados e alienados, não possuem condições reais de oferecer a atenção e as boas práticas recomendadas pela OMS, por falta de capacitação, instrução, tempo e estímulo da própria gestão dos hospitais.

0 presente estudo tem por objetivo realizar uma revisão integrativa da literatura, de artigos publicados na plataforma LILACS e, baseando-se no método histórico dialético, buscar estabelecer uma relação entre a precarização das relações trabalhistas na saúde e os altos índices de violência obstétrica sofridos pelas gestantes nas maternidades brasileiras.

\section{MÉTODO}

Trata-se de uma revisão integrativa da literatura acerca de material científico encontrado na plataforma de busca LILACS, com o descritor "violência obstétrica", realizada no período de junho a agosto de 2018, que utilizou a teoria marxiana como referencial teórico.

Num primeiro momento, recorreu-se a um levantamento pelo descritor e, num segundo, considerou-se as produções de 2013 a 2017. Os artigos considerados foram lidos, analisados e descritos, especificando o autor/ano de publicação, título, objetivo, metodologia e resultados. Foram descartadas produções internacionais, aquelas que não atendiam à temática e/ou que não estavam na íntegra online.

Numa segunda busca, na mesma plataforma de dados e período, buscou-se o descritor "Trabalho precarizado", no sentido de correlacionar essa categoria à da violência obstétrica.

\section{RESULTADOS}

Foram localizados, inicialmente, 60 documentos, sendo: 52 artigos científicos, 6 teses, uma monografia e um documento de projeto, datados de 1999 a 2018. Ao se considerar o período elencado, atingiu-se 42 documentos. Desses, 13 foram descartados por não apresentarem pesquisas relacionadas ao Brasil e um não teve o texto localizado na íntegra, não sendo possível sua leitura. Dos 28 documentos restantes, 15 não tratavam da violência obstétrica sob a perspectiva institucional, restando 13 documentos e 1 documento voltado ao trabalho precarizado, habilitados então para a pesquisa.

Desses artigos, 2 abordavam a violência obstétrica sob o ponto de vista dos profissionais $\left.{ }^{*}\right), 7$ sob o ponto de vista das mulheres puérperas $\left(^{* *}\right)$ e 5 traziam uma revisão da literatura acerca do tema $\left({ }^{* *}\right)$, conforme Quadro 1.

Quadro 1. Artigos sobre violência obstétrica institucional de janeiro de 2013 a 2017. São Paulo, junho a agosto de 2018.

\begin{tabular}{|c|c|c|c|c|}
\hline Autor (ano) & Título & Objetivo & Metodologia & Resultados \\
\hline $\begin{array}{l}\text { Aguiar }^{7} \\
(2013) \\
\text { Visão dos } \\
\text { profissionais* }\end{array}$ & $\begin{array}{l}\text { Violência } \\
\text { institucional, } \\
\text { autoridade } \\
\text { médica e o poder } \\
\text { nas } \\
\text { maternidades } \\
\text { sob a ótica dos } \\
\text { profissionais de } \\
\text { saúde }\end{array}$ & $\begin{array}{ll}\text { Discutir } & \text { a } \\
\text { violência } & \\
\text { institucional sob } \\
\text { a ótica dos } \\
\text { profissionais. }\end{array}$ & $\begin{array}{lr}\text { Uso de roteiro } \\
\text { semiestruturado. } \\
\text { Foram realizadas } \\
\text { entrevistas com } & 21 \\
\text { puérperas e } & 18 \\
\text { profissionais } & \text { da } \\
\text { saúde, }(10 \text { obstetras, } \\
5 \text { enfermeiras e } 3 \\
\text { técnicas } & \text { de } \\
\text { enfermagem), em } \\
\text { um hospital na } \\
\text { cidade de São Paulo. }\end{array}$ & $\begin{array}{l}\text { Revelou o reconhecimento dos } \\
\text { profissionais de práticas } \\
\text { discriminatórias } \\
\text { desrespeitosas no cotidiano da } \\
\text { assistência às gestantes. } \\
\text { Práticas que são percebidas } \\
\text { como violentas, mas que estão } \\
\text { banalizadas, travestidas de } \\
\text { boas. }\end{array}$ \\
\hline $\begin{array}{l}\text { Leal }^{8} \\
(2018) \\
\text { Visão dos } \\
\text { profissionais* }\end{array}$ & $\begin{array}{ll}\text { Percepção } & \text { de } \\
\text { enfermeiras } & \\
\text { obstétricas } & \\
\text { acerca } & \text { da } \\
\text { violência } & \\
\text { obstétrica } & \end{array}$ & $\begin{array}{lr}\text { Conhecer } & \text { a } \\
\text { percepção } & \text { de } \\
\text { enfermeiras } & \\
\text { obstétricas } & \\
\text { acerca } & \text { da } \\
\text { violência } & \\
\text { obstétrica de } & \text { um } \\
\begin{array}{ll}\text { Centro } \\
\text { Obstétrico na }\end{array}\end{array}$ & $\begin{array}{l}\text { Dados coletados em } \\
\text { entrevistas } \\
\text { semiestruturadas, } \\
\text { realizadas com } 19 \\
\text { enfermeiras } \\
\text { obstétricas, entre } \\
\text { abril e maio de } 2016 .\end{array}$ & $\begin{array}{l}\text { As enfermeiras obstétricas } \\
\text { percebem que a violência se } \\
\text { apresenta de várias formas. } \\
\text { Entretanto, não reconhecem } \\
\text { determinadas práticas como } \\
\text { violência. O estudo vislumbrou } \\
\text { a necessidade de estratégias } \\
\text { preventivas à ocorrência da } \\
\text { violência obstétrica. }\end{array}$ \\
\hline
\end{tabular}

cidade de Belém,

Pará. 


\section{Rodrigues $^{9}$} (2016)

Visão mulheres**
Violência

obstétrica

das processo

parturição maternidades vinculadas Rede Cegonha
Analisar

no violência

de institucional

em contra mulheres no processo de

à parturição em maternidades da Rede Cegonha de Fortaleza e

Cascavel.

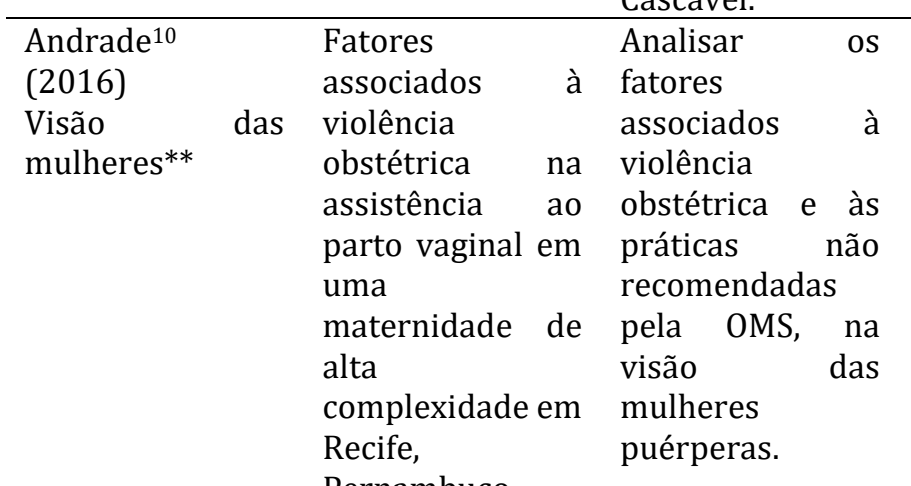
Pernambuco

\begin{tabular}{llll}
\hline Pedroso $^{11}$ & À margem da & Conhecer acerca \\
$(2017)$ & humanização? & das experiências \\
Visão & das & Experiências de & das mulheres em \\
mulheres** $^{*}$ & parto de usuárias & relação & à \\
& de uma & assistência a \\
& maternidade & parto. & \\
& pública de Porto & \\
& Alegre/RS &
\end{tabular}

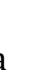

a com abordagem quantitativa, realizado em 11 hospitaismaternidades, com a participação de 3.765 puérperas, de novembro 2013 a janeiro 2014.

Estudo transversal Prevalência de violência
com 603 puérperas, obstétrica em 86,57\% das realizado de agosto a mulheres atendidas. dezembro de 2014
A pesquisa demonstra a importância de um atendimento humanizado adequado por meio da estruturação e organização da atenção materno-infantil proposto pela Rede Cegonha.

das




\section{Souza $^{5}$}

(2016)

Revisão

literatura***
Fatores

associados

da ocorrência

violência

obstétrica

institucional:

uma revisão

integrativa $\mathrm{da}$

literatura

$\operatorname{Diniz}^{1}$

(2014)

Revisão Literatura*** $^{* *}$

Violência
Obstétrica como complexa

da questão para a

saúde pública no

Brasil: origens, definições, tipologia, saúde materna, e serviços de saúde propostas para e as implicações sua prevenção na

morbimortalidade materna.

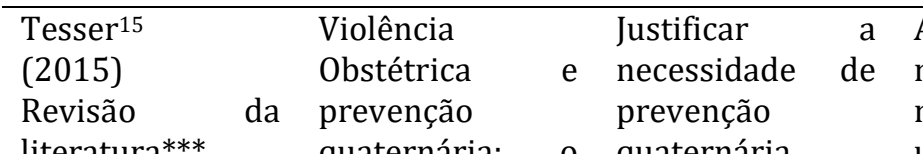

literatura*** quaternária: o quaternária que é e o que frente à violência fazer

Dados adquiridos Constatou-se que os por meio de seleção profissionais descritos como nas plataformas promotores da violência foram Lilacs, MedLine, os médicos, equipe de Scielo e Google enfermagem e estudantes de acadêmico, medicina.

composta de 20 artigos publicados

entre 2010 e 2016. narrativa sobre o que é necessário acontecer tema, abarcando a algumas mudanças na formação literatura dos recursos humanos durante acadêmica, a graduação e especialização produções dos dos médicos, com uso de movimentos sociais bibliografias mais atualizadas. e documentos Difundir informações sobre institucionais, do assistência ao parto, garantir o Brasil e exterior. direito a acompanhante, fomentar pesquisas na área $\mathrm{e}$ incluir a assistência ao abortamento seguro.

Artigo original que Apresenta como propostas três não especifica a ações: 1) elaboração de planos metodologia de parto orientados; 2) utilizada. introdução de outros profissionais qualificados no cuidado ao parto e 3) participação dos Médicos de Família e Comunidade (MFC) e profissionais da APS no movimento social e político pela humanização do parto

\begin{tabular}{|c|c|c|c|c|}
\hline $\begin{array}{l}\text { Zanardo } 16 \\
\text { (2017) } \\
\text { Revisão } \\
\text { literatura*** }\end{array}$ & $\begin{array}{l}\text { Violência } \\
\text { obstétrica no } \\
\text { Brasil: uma } \\
\text { revisão narrativa }\end{array}$ & $\begin{array}{l}\text { Realizar uma } \\
\text { revisão narrativa } \\
\text { de estudos sobre } \\
\text { violência } \\
\text { obstétrica. }\end{array}$ & $\begin{array}{lr}\text { Artigo que } & \text { não } \\
\text { especifica } & \text { a } \\
\text { metodologia } & \\
\text { utilizada. } & \end{array}$ & $\begin{array}{l}\text { Os dados apontam para a } \\
\text { necessidade de } \\
\text { conceituação de violência } \\
\text { obstétrica, preferencialmente } \\
\text { em documentos legais que a } \\
\text { definam e criminalizem. }\end{array}$ \\
\hline $\begin{array}{l}\text { Barbosa }^{17} \\
\text { (2017) } \\
\text { Revisão } \\
\text { literatura*** }\end{array}$ & $\begin{array}{l}\text { Violência } \\
\text { obstétrica: } \\
\text { revisão } \\
\text { integrativa } \\
\text { pesquisas } \\
\text { qualitativas }\end{array}$ & $\begin{array}{l}\text { Realizar revisão } \\
\text { integrativa de } \\
\text { pesquisas } \\
\text { qualitativas. }\end{array}$ & $\begin{array}{l}\text { A partir das bases } \\
\text { escolhidas, foram } \\
\text { encontrados } 17051 \\
\text { artigos, após os } \\
\text { critérios } \\
\text { estabelecidos } \\
\text { restaram 54. }\end{array}$ & $\begin{array}{l}\text { As práticas de assistência ao } \\
\text { parto no Brasil desrespeitam os } \\
\text { direitos sexuais e reprodutivos, } \\
\text { o que se reflete nos altos índices } \\
\text { de cesáreas desnecessárias e } \\
\text { nos maus tratos sofridos pelas } \\
\text { mulheres nas maternidades } \\
\text { brasileiras. }\end{array}$ \\
\hline
\end{tabular}

Com relação ao termo "Trabalho precarizado", 13 trabalhos foram localizados, sendo 10 artigos científicos e 3 teses, mas somente 1 tratava do trabalho precarizado na

saúde. Portanto, apesar de datar de 2011 foi considerada a sua leitura por ser o único a abordar o tema (Quadro 2).

Quadro 2. Artigos sobre trabalho precarizado 2011. São Paulo, junho a agosto de 2018.
Autor (ano)

Silva ${ }^{18}$ 2011

Título

trabalhadores

em contexto

de

precarização:

um estudo de

caso

serviços de

emergência

de hospital

universitário
Vivências de

\section{Objetivo} cotidiano dos laborativas

trabalhadores

do setor de

$\begin{array}{lr}\text { profissionais } & \text { de } \\ \text { enfermagem e serviço }\end{array}$

com emergências do Hospital

Universitário

Antônio Pedro em Niterói/ RJ

social, destacando suas

vivências por meio de

análise construída pelo

dispositivo da Comunidade

Ampliada de Pesquisa.
Grupo com 10

trabalhadores, encontros

mensais de $2 \mathrm{~h}$, realizados

de abril a setembro 2011.

Resultados

Observou-se grande dificuldade na construção de ambiente favorável às vivências de prazer e realização profissional decorrente da política vigente de desmonte do setor, das contratações temporárias e ambiente precarizado. Essas dificuldades encaminhavam para o sofrimento psíquico no trabalho numa dimensão patogênica. 


\section{DISCUSSÃo}

Pelos documentos levantados, a violência obstétrica é praticada em todo o Brasil12,17 e, muitas vezes, se mostra travestida de boas práticas $5,7,11$, pelo desconhecimento da prática de atos considerados como violência obstétrica pela equipe médica e pela parturiente ${ }^{1,8,14,16}$.

Apesar da violência obstétrica ser um termo novo ${ }^{17}$, muitos são os artigos tratando do assunto, que já se encontra muito bem organizado em seus conceitos, tipificações e definições do que é ou não violência 1,5,7-12,14,16.

Os resultados da pesquisa apontam no sentido de uma urgente prática humanizadora do momento do parto. Porém, as dificuldades são inúmeras, pois o modo como o sistema de saúde está estruturado, no modelo atual da sociedade capitalista, que visa o lucro em detrimento do bem-estar social, não favorece a mudança necessária ${ }^{8,9,12,15}$.

As atuais relações trabalhistas, com a precarização da mão de obra, a alienação do trabalhador, a expropriação dos direitos trabalhistas, os trabalhos temporários, a falta de capacitação e treinamento, criam um ambiente patogênico, adoecem os trabalhadores e os tornam vulneráveis e aptos a praticarem violência, por desconhecimento da própria configuração dessa violência, além do cansaço e desestímulo. Em um contexto de precariedade social, o sentido e a importância do trabalho se perdem ${ }^{18}$.

Percebeu-se a ausência de artigos que relacionem a precarização do trabalho com a prática da violência obstétrica, o que pode ser explicado justamente pela banalização da violência.

A saúde no Brasil é regida atualmente pelo modelo hospitalocêntrico ${ }^{14}$ curativo e centrado na doença, no qual há uma fragmentação e hierarquização do processo de trabalho em saúde, com a proliferação das especialidades médicas, opondo ações que incorporem a articulação intersetorial, abordagens interdisciplinares e a participação social.

Antes do modelo atual, a saúde pública no Brasil percorreu um longo caminho e seguiu diversos modelos. No início do século XIX, havia o modelo biomédico, que associava doença a lesão, tendo uma visão reduzida de saúdedoença, sem considerar as suas dimensões sociohistóricas ${ }^{19}$.

Em 1923 ocorreu a Reforma Carlos Chagas. 0 modelo de saúde naquela época era o denominado previdenciário-privatista, sob a influência da medicina liberal. Esse modelo ofertava assistência médico-hospitalar a trabalhadores urbanos e industriais por meio do seguro de saúde/previdência. Tratava-se de um modelo de orientação contencionista ${ }^{19}$.

No final do século passado, o modelo se modificou para o preventista, expandindo o paradigma microbiológico da doença para a população, visando à organização e à higienização das pessoas e espaços públicos e privados. Esse modelo predominou até a década de $1960^{19}$.

Entretanto, nasceu no contexto da luta contra a ditadura o movimento da Reforma Sanitária, no início da década de 1970. A expressão foi usada para se referir ao conjunto de ideias que se tinha em relação às mudanças e transformações necessárias na área da saúde. Essas mudanças não abarcavam apenas o sistema, mas todo o setor de saúde, em busca da melhoria das condições de vida da população ${ }^{19}$.

A Constituição Federal de 1988 traz em seu art. 6ํ que a saúde é um direito social, e o art. 196 acrescenta que o mesmo deve ser garantido pelo Estado através de políticas públicas. A Constituição fez nascer o Sistema Único da Saúde, o SUS ${ }^{19}$.

Em 2018 o SUS completou 30 anos desde sua criação, e está presente em 100\% do território nacional. Dados ${ }^{20}$ confirmam o modelo hospitalocêntrico da saúde no Brasil, ao demonstrar que $67,6 \%$ das pessoas procuram o SUS para tratarem de doença, e 27,9\% para prevenção, enquadrando nesse item o prénatal. Segundo a mesma pesquisa, 66,8\% da população é feminina, predominam os pretos e pardos com 56\%, e 66,5\% têm entre 15 e 59 anos. Dessa população, $88,8 \%$ não possuem plano de saúde privado.

$\mathrm{Na}$ lógica do capital, a saúde está sofrendo cada vez mais a influência do mercado privado em âmbito mundial, com o rápido crescimento da oferta da saúde privada, pois apesar do SUS se reafirmar como política e a Constituição garantir acesso à saúde a todos, é inegável o sucateamento dos serviços por ele oferecidos, e há uma forte tendência do SUS deixar de ser universal.

As produções sobre o tema ${ }^{16-21}$ mostram que até o final do século XVIII o parto era um ritual natural e comum na vida das mulheres. Ele era realizado na própria casa da mulher gestante e com o acompanhamento de parteiras e outras mulheres da família e da comunidade. No final do século XIX, inicia-se um processo de mudança por meio das tentativas de controle do evento biológico por parte da obstetrícia, que deixa de ser da esfera do feminino e passa a ser compreendida como uma prática médica ${ }^{22}$.

Com a implantação das escolas de medicina no Brasil Império, houve um esforço da corporação médica para tornar agradável a figura do médico obstetra, para que as mulheres passassem a confiar neles, ao mesmo tempo em que o discurso da época se dirigia à mulher como o sexo frágil, vendo-a como sensível, pacífica, terna e delicada. Surge nessa época a construção do "mito do amor materno", da "mãe dedicada, boa esposa e rainha do lar"21, que permanece atual ainda nos dias de hoje, fácil de 
lembrar pela matéria publicada na revista Veja em abril de 2016, que elogiava a então futura primeira dama do Brasil, Marcela Temer, com os atributos "bela, recatada e 'do lar".

Diante disso, é fácil perceber a relação entre a construção histórica de fragilização da figura feminina com a forma como a medicina tem se apropriado disso, por meio do processo do parto, na medida em que assumiu o controle sobre o corpo das mulheres e as levou para parir nos hospitais, ainda que em condições precárias. A introdução da medicina nesse espaço inaugurou não só a experimentação clínica articulada com o discurso anatomopatológico, mas também um discurso que proporciona a penetração da figura masculina no saber e na prática obstétrica ${ }^{21}$. Nascer em maternidades tornou-se algo comum e não questionado pela maioria das mulheres na contemporaneidade.

Nascer em ambiente hospitalar é um contrassenso, uma vez que no modelo de saúde do Brasil, o hospitalocêntrico, concentra-se nas unidades hospitalares um grande número de pessoas com doenças, realizando diversos tipos de tratamentos, e nascer é saúde, é vida, a maternidade pode muitas vezes oferecer mais riscos do que benefícios à parturiente e ao recém-nascido, como contaminações e infecções.

A mulher, ao deixar de ser protagonista de seu trabalho de parto (por ter incorporado as ideias do discurso de ser frágil), passa a ser mera coadjuvante no processo, uma vez que agora os protagonistas são o médico obstetra e sua equipe médica. Ela passa a ser objeto passível de sofrer violência, no caso, obstétrica.

Além dos riscos inerentes ao ambiente hospitalar, dados alarmantes foram divulgados em $2010^{6}$ sobre violência obstétrica. Eles afirmam que $25 \%$ das parturientes foram vítimas de violência obstétrica, por parte dos profissionais da saúde.

É possível compreender que no Brasil o conceito de violência vem sendo utilizado para descrever e agrupar diversas formas de violência (e danos) durante o cuidado obstétrico profissional. Inclui maus tratos físicos, psicológicos e verbais, assim como procedimentos desnecessários e danosos ${ }^{15}$, ou seja, a manipulação e exposição desnecessária do corpo da mulher, bem como a violação dos seus direitos, o que inclui perda da autonomia e decisão sobre seus corpos.

A partir do momento em que a mulher encarna a figura de mulher frágil, fruto de uma construção histórica nascida no Brasil Império e reafirmada exaustivamente até os dias atuais, ela própria abre mão de ser protagonista do seu corpo e passa a aceitar os mandos médicos, acreditando ser o melhor para aquele momento, e que a medicina tem eficácia nesse processo, e muitas vezes a parturiente não tem consciência de que está sofrendo uma violência obstétrica.

Pesquisas apontam que se tem medicalizado o parto, utilizando em larga escala procedimentos considerados inadequados e desnecessários $^{22}$, que colocam a vida da gestante e do bebê em risco, pois já está comprovado que as intervenções não possuem evidências científicas.

Quanto à atenção destinada no momento do parto, existem, atualmente, três modelos ${ }^{6}$, o altamente medicalizado, com uso de alta tecnologia e pouca participação de obstetrizes, encontrado nos Estados Unidos, Irlanda, Rússia, República Tcheca, França, Bélgica e regiões urbanas do Brasil; o modelo humanizado, com maior participação de obstetrizes e menor frequência de intervenções, encontrado na Holanda, Nova Zelândia e países escandinavos; e os modelos mistos, encontrados na GrãBretanha, Canadá, Alemanha, Japão e Austrália.

O Senado Federal publicou em 2012 um dossiê, denominado "Violência Obstétrica Parirás com dor ${ }^{24 ", ~ e l a b o r a d o ~ p e l a ~ R e d e ~ P a r t o ~}$ do Princípio, para a Comissão Parlamentar Mista de Inquérito (CPMI) da Violência contra as Mulheres. Nele encontram-se, de forma detalhada, os tipos de violência que mais ocorrem nas maternidades brasileiras ${ }^{24}$ :

a) Episiotomia - trata-se de um corte no períneo, realizado com bisturi ou tesoura, feito rotineiramente, e sem respaldo científico quanto à sua eficácia. Na maioria das vezes, é feito sem anestesia e sem o consentimento da parturiente. Tão grave quanto a realização da episiotomia é a sutura denominada "ponto do marido", que tem a função de deixar a vagina bem apertada, para "preservar" o prazer masculino nas relações sexuais depois do parto; b) Intervenções de verificação e aceleração do parto - utilização rotineira de ocitocina sintética (hormônio sintético que acelera o trabalho de parto, causando dores terríveis, que fazem as parturientes implorarem pela cesárea); rompimento artificial da bolsa; dilatação manual do colo para acelerar a dilatação; comandos de puxos; fórceps e manobra de Kristeller, que consiste em uma manobra na qual uma pessoa da equipe médica, utilizando as duas mãos, ou subindo em cima da mulher, ou espremendo seu ventre com o peso do corpo sobre as mãos, braço, antebraço ou joelho, empurra a barriga da gestante em direção à pelve e força o nascimento;

c) Jejum, inclusive de água - essa prática não tem respaldo científico e só serve para deixar a mulher cansada e desidratada;

d) Restrição de posição para o parto - existe uma prática que supõe que a mulher deve parir deitada. A orientação da OMS e da Agência Nacional de Vigilância Sanitária (ANVISA) é de que a mulher deve ter liberdade para escolher a posição em que se sinta mais confortável; 
e) Atos de desrespeito e exposição do corpo em muitas maternidades, as mulheres ficam todas juntas, sem divisórias; os exames de toque para verificar a dilatação são realizados rotineiramente sem privacidade alguma;

f) Violência psicológica - compreendida como descaso, abandono, desprezo, humilhação, ameaça, coação, preconceito, discriminação por raça, etnia, classe social, homofobia, assédio, sadismo, culpabilização, chantagem;

g) Violência física;

h) Violência sexual.

Um estudo de 2014, uma pesquisa denominada Desigualdades sociais e satisfação das mulheres com o atendimento ao parto no Brasil: estudo nacional de base hospitalar ${ }^{24}$, entrevistou o número considerável de 23.523 mulheres brasileiras parturientes e chegou a constatações muito interessantes:

- a primeira é que, quanto maior a escolaridade da parturiente, mais respeito por parte dos profissionais da saúde, mais privacidade nos exames e maior clareza nas explicações dadas a ela;

- a segunda é que nos hospitais privados houve menos relatos de violência obstétrica e maior grau de satisfação, além de melhor relacionamento com os profissionais, o que fere o princípio da equidade na assistência à saúde.

Esse dado pode ser interpretado pelo fato de que as mulheres que fazem o pré-natal na rede privada desenvolvem, geralmente, um vínculo com seu obstetra e, no momento do parto, estão mais confiantes. 0 modelo de atendimento do SUS não permite à gestante a garantia de ser atendida sempre pelo mesmo médico, muito menos de tê-lo no momento do parto.

Outra constatação da pesquisa é com relação à autonomia da parturiente. Foi observado que na rede pública existe uma cultura discriminatória que considera as mulheres de baixa renda e escolaridade como incapazes de decidir sobre as intervenções no parto, o que permite entender a primeira informação dos relatos de menor clareza nas explicações, ou seja, a equipe não escuta e não conversa com as parturientes ${ }^{24}$.

O cenário de violência obstétrica é naturalizado tanto para as mulheres quanto para os profissionais. Um estudo ${ }^{7}$ realizado pela Faculdade de Medicina da Universidade de São Paulo, entrevistou 18 profissionais da saúde e observou que a banalização da violência [obstétrica] institucional é travestida de boa prática profissional e exercício pretensamente legítimo de autoridade, de acordo com as respostas das entrevistadas, que não reconheciam as práticas de violência como atos violentos.

Outra prática recorrente nas maternidades é a prática desmedida de cesarianas. Os índices no Brasil são altíssimos há décadas, e pesquisas apontam que em 2012 representavam $85 \%$ dos partos no setor privado ${ }^{25}$.

A cesárea é uma intervenção efetiva para salvar a vida de mães e bebês, mas apenas quando indicada por motivos médicos. Antes de existir esse procedimento, muitas gestantes faleciam no parto por complicações. É por esse motivo que a OMS considera que 10 a 15\% das mulheres necessitam passar por ela ${ }^{26}$ para garantir a sobrevivência própria e do recémnascido.

Entre os potenciais riscos associados à cirurgia cesariana está o nascimento prematuro. A prematuridade é reconhecida como um dos determinantes da mortalidade infantil. Bebês nascidos de 37 a 38 semanas de gestação, quando comparados a bebês de 39 a 40 semanas, apresentam 120 vezes mais chances de necessitar de suporte ventilatório. Além das complicações para os bebês, a gestante também está exposta a vários riscos, pois se trata de uma cirurgia de médio porte. Há risco de sangramentos, complicações e infecções ${ }^{27}$.

Há no Brasil uma cultura da cesárea na classe médica, conforme apontou uma pesquisa $^{27}$ na qual $75,6 \%$ das mulheres, quando entrevistadas, disseram não querer a cesárea. Dentre as razões, as mulheres informam que o pós-operatório é muito complicado e dolorido. Isso demonstra que a mulher não é a protagonista no trabalho de parto, já que a maioria das mulheres que sofreram cesárea não a solicitaram. Ao mesmo tempo, 19\% das que tiveram parto vaginal reportaram que haviam pedido cesárea. Isso revela o poder limitado das mulheres em determinar o tipo de parto que vão fazer, seja ele vaginal ou cesárea.

A mesma pesquisa ${ }^{27}$ demonstrou que, durante a evolução do trabalho de parto natural, uma grande porcentagem das mulheres que estavam internadas há muito tempo - entre 6 e 12 horas - solicitaram a cesárea, e isso se devia ao fato de a maternidade não cumprir as boas práticas que deveriam ser adotadas. Se não forem cumpridas condições mínimas e simples práticas que promovem o conforto e bem-estar da parturiente, a estadia na maternidade em trabalho de parto se torna sofrida, e a cesárea passa a ser uma opção a ser considerada para acabar logo com o sofrimento.

Outra pesquisa indica que os grupos de pessoas ativistas que lutam pela humanização do parto $^{12}$ começaram com mulheres insatisfeitas (talvez vítimas de violência) e com profissionais com dificuldades em prestar um atendimento com cuidado humanizado. Com o advento da internet nos anos de 1990, esses movimentos vêm adquirindo força no Brasil e no mundo. Com uma rápida pesquisa em sites de busca, é fácil visualizar os inúmeros grupos e 
Organizações Não Governamentais (ONGs) que defendem a prática do parto humanizado ${ }^{12}$.

Atualmente têm surgido alguns movimentos pela humanização no atendimento, e em especial pela humanização no parto. Quando se vê o surgimento de tais movimentos, é inevitável pensar que eles só surgem em situações nas quais há a desumanização de algo. Pensando no contexto histórico se vê que quando as mulheres pariam em suas casas não havia violência, o ambiente era conhecido e acolhedor, havia ajuda e troca mútuas entre as envolvidas no trabalho de parto.

Pesquisa indica que a humanização exige uma transformação profunda do modelo de assistência, da relação dos profissionais da saúde com as gestantes ${ }^{11}$, para horizontalizar a relação entre médico e paciente, favorecendo o protagonismo da mulher, pois o atual modelo de atendimento ao parto no Brasil está se transformando em um modelo reprodutor de violência institucional, que reforça a estigmatização de que a mulher é frágil e o parto um momento de muito sofrimento.

O trabalho precarizado no Brasil vem se afirmando como uma tendência há algumas décadas, por meio da terceirização de mão de obra. Atualmente, com a reforma trabalhista em 2016 e a legalidade da terceirização não só nas atividades meios, como também nas atividades fins, os processos de trabalho ficarão cada vez mais precários e alienados, já que a terceirização transfere a atividade de um "primeiro" - que deveria se responsabilizar pela relação empregatícia - para um "terceiro", liberando, assim, o grande capital dos encargos e direitos trabalhistas ${ }^{7}$.

Travestido sob o mantra da parceria e da cooperação, as relações trabalhistas fragilizadas afetam as relações sociais e a sociedade como um todo, o que provoca uma consequente alienação social do trabalho. 0 trabalho deixa de representar a categoria fundante do ser social, pois, nessa sociedade, e firma-se o processo de coisificação das relações humanas. Passa, então, a existir um individualismo exacerbado, consumista e desintegrador, por meio do qual os indivíduos passam a se sentir cada vez mais sozinhos, perdendo seus próprios valores e a noção de pertencimento à espécie humana7.

É importante pensar nos possíveis motivos que levaram a sociedade a caminhar na direção oposta ao trabalho como categoria fundante do ser social. Estudos ${ }^{7}$ indicam três possibilidades: 1) Trabalho e adoecimento, como um problema de saúde pública; 2) Trabalho e degradação, devastando as reservas naturais; 3) Trabalho e precarização social, que compromete gerações, privando-as de educação e trabalho digno, gerando violência social.
A sociedade encontra-se tão bem desenvolvida tecnologicamente que teria condições de viver em harmonia com a natureza e o próximo, se não fosse o mundo da produção contínua, predominantemente estruturado e se movendo pela acumulação de capital e lucro ${ }^{7}$. Daí se pode afirmar que a forma como a sociedade está estruturada leva os indivíduos à expropriação de sua dignidade e os torna alienados nesse processo.

A relação que se estabelece das condições de trabalho atuais com os profissionais da saúde é estreita e correlata, pois todos estão inseridos nessa lógica mercadológica. Com a pesquisa foi possível auferir que a jornada de trabalho dos profissionais representa 40 horas no mínimo e 60 no máximo para os obstetras, e de 40 a 72 horas semanais para as enfermeiras. A sobrecarga de demandas, as condições estruturais e a precariedade de recursos materiais foram apontadas como dificuldades enfrentadas cotidianamente pelos profissionais $^{18}$.

Além disso, muitos profissionais atendem no sistema de plantões, trabalhando 24 horas direto, o que vem a ser uma contradição com seu biorritmo, favorecendo o adoecimento do profissional, bem como a maior incidência de erros médicos e acidentes ${ }^{7}$.

Nessas condições torna-se notável o agudizamento do capital nas relações sociais. Primeiro no modelo atual de atenção à saúde hospitalocêntrico, que levou as mulheres a parirem sem autonomia e protagonismo, e com isso favorecendo a medicalização e intervenções excessivas, num modelo hierárquico de autoridade médica. E segundo na transformação de profissionais da saúde em agentes de violência devido às suas próprias condições de precariedade, uma vez que se encontram inseridos na lógica mercadológica de alienação do trabalho, o que resulta não só no esgotamento físico e emocional do profissional, mas também na dificuldade de refletir sobre sua prática ${ }^{7}$.

Compreende-se saúde, na sua concepção ampliada, trazida pela 8ª Conferência Nacional em Saúde ${ }^{28}$, não somente como a ausência de doença, mas sim como o resultado de boas condições de alimentação, habitação, educação, renda, meio ambiente, trabalho, transporte, emprego, lazer, liberdade, acesso e posse da terra, acesso a serviços de saúde, e ainda como resultado das formas de organização social da produção, as quais podem gerar desigualdades nos níveis de vida.

Nesse caso, há um binômio adverso. Se, de um lado, há a saúde (em seu conceito ampliado) e a necessidade primária dos homens, de outro há a estrutura do capital, que retira dos trabalhadores essa premissa da vida, 
a saúde, por meio de modos de produção exploratórios da força de trabalho.

Do ponto de vista dessa perspectiva, os profissionais envolvidos na área da saúde (área complexa que requer vários conhecimentos, experiências e saberes) precisam expandir o olhar para além das aparências, para que a saúde seja compreendida como uma produção social.

Percebe-se que existe um conjunto de fatores que influenciam a forma de vir ao mundo na contemporaneidade. A medicalização do parto (que foi um processo sociocultural complexo, que transformou o que antes era inerente e comum às mulheres em uma necessidade médica, permeada pelo sofrimento, por dores e que levou ao declínio da capacidade da mulher em lidar com o fenômeno do trabalho de parto, questões essas que eram administradas no próprio ambiente familiar e comunitário como algo natural), associada às precárias condições de trabalho dos profissionais da saúde e à desvalorização da mulher, no sentido de torná-la coadjuvante no processo do trabalho de parto, resultam em violência obstétrica.

0 capitalismo atingiu até mesmo a forma de nascer, com a aplicação de processos desumanos e permeados de violência. Mas como é possível agir com humanidade quando os próprios trabalhadores muitas vezes vivem vidas tão precarizadas?

\section{CONCLUSÃO}

As limitações deste estudo estão ligadas ao fato de que houve uma única base e período restrito. No entanto, a revisão em questão apresentou 14 produções direcionadas à precarização das relações trabalhistas na saúde e à violência obstétrica sofrida pelas gestantes nas maternidades brasileiras, com destaque para os interesses do capital afetando fortemente a forma de vir ao mundo.

Desde o Brasil Império, paira no ar a cultura patriarcal de tornar a mulher o sexo frágil, e incutir a ideia de que ela não consegue parir de forma natural e,, pela via da cesárea os médicos organizam suas agendas, mantendo o índice elevadíssimo de cesáreas desnecessárias, conforme demonstram as pesquisas citadas.

Porém, para erradicar a violência obstétrica, reduzir os altos índices de cesáreas desnecessárias e, ao mesmo tempo, melhorar as condições de vida e de trabalho do profissional da saúde, não bastam somente políticas públicas. É preciso modificar o modelo de atenção ao parto por completo. Os hospitais necessitam passar por adequações das estruturas físicas, por contratações de profissionais, sobretudo de obstetrizes, enfermeiras obstetras e doulas (mulheres que dão suporte físico e emocional às parturientes), lançando mão de médicos e enfermeiras somente se houver indicação real de intervenção, pois percebe-se que a violência é resultado da própria precariedade do sistema de saúde no Brasil.

Além desses apontamentos, entende-se como necessário tratar da questão da humanização no atendimento médico na formação acadêmica do estudante de medicina, como base obrigatória curricular, além de capacitações continuadas aos profissionais da saúde.

Entende-se ainda que todas essas medidas são paliativas, no sentido de diminuir os índices absurdos de $25 \%$ de mulheres vítimas de violência obstétrica, uma vez que a pesquisa apontou estreita relação entre a prática da violência obstétrica e as péssimas condições às quais os profissionais da saúde estão submetidos.

Portanto, através da pesquisa realizada, foi possível auferir que existe uma relação direta entre a violência obstétrica e os limites extrapolados do capital, que expropria dos trabalhadores até mesmo as condições mínimas de sobrevivência e humanidade, retirando a capacidade de enxergar o sofrimento humano alheio, banalizando e naturalizando a violência e deixando de se indignar com as expressões da questão social que permeiam o cotidiano de trabalho e das mulheres atendidas na rede de saúde.

\section{REFERÊNCIAS}

1. Diniz SG, Salgado HO, Andrezzo HFA, Carvalho PGC, Carvalho PCA, Aguiar CA, et al. Violência obstétrica como questão para a saúde pública no Brasil: origens, definições, tipologia, impactos sobre a saúde materna, e propostas para sua prevenção. J Hum Growth Dev. [Internet]. 2015 [citado em 05 ago 2018]; 25(3):377-6.

http://dx.doi.org/10.7322/jhgd.106080

2. Lessa $S$, Tonet I. Introdução à filosofia de Marx. São Paulo: Expressão Popular; 2008.

3. Marx K. O capital. São Paulo: Nova Cultural; 1996. t.1, v.I

4. Pereira P. Necessidades humanas: subsídios à crítica dos mínimos sociais. 6ed. São Paulo: Cortez; 2011. p.83

5. Souza AB, Silva LC, Alves RN, Alarcão ANJ. Fatores associados à ocorrência de violência obstétrica institucional: uma revisão integrativa da literatura. Rev Ciênc Méd. [Internet]. 2016; 25(3):115-28. Disponível em: https://seer.sis.puc-

campinas.edu.br/seer/index.php/cienciasmedi cas/article/view/3641

6. Martinelli ML. 0 trabalho do assistente social em contextos hospitalares: desafios cotidianos. Revista Serv Soc Soc. [Internet]. 2011 [citado em 08 ago 2018]; 107:497-508. Disponível em: http://www.scielo.br/pdf/sssoc/n107/07.pdf 
7. Aguiar JM, Oliveira AFPL, Schraiber LB. Violência institucional, autoridade médica e poder nas maternidades sob a ótica dos profissionais de saúde. Cad Saúde Pública. [Internet]. 2013 [citado em 16 ago 2018]; 29(11):2287-96.

http://dx.doi.org/10.1590/0102-

311X00074912

8. Leal SYP, Lima VLA, Silva AF, Soares PDFL, Santana LR, Pereira A. Percepção de enfermeiras obstétricas acerca da violência obstétrica. Cogitare Enferm. [Internet]. 2018 [citado em 08 ago 2018]; 23(2):e52473. DOI: http://dx.doi.org/10.5380/ce.v23i1.52473

9. Rodrigues FAC, Lira SVG, Magalhães $\mathrm{PH}$, Freitas ALV, Mitros VMS, Almeida PC. Violência obstétrica no processo de parturição em maternidades vinculadas à Rede Cegonha. Reprod Clim. [Internet]. 2017 [citado em 05 ago 2018]; 32(2):78-84. DOI: http://dx.doi.org/10.1016/j.recli.2016.12.001 10. Andrade PON, Silva JQP, Diniz CMM, Caminha MFC. Fatores associados à violência obstétrica na assistência ao parto vaginal em uma maternidade de alta complexidade em Recife, Pernambuco. Rev Bras Saúde Mater Infant. [Internet]. 2016 [citado em 08 ago 2018]; 16(1):29-37. DOI: http://dx.doi.org/10.1590/1806-

93042016000100004

11. Pedroso CNLS, López LC. À margem da humanização? Experiências de parto de usuárias de uma maternidade pública de Porto Alegre/RS. Physis. [Internet]. 2017 [citado em 08 ago 2018]; 27(4):1163-84. DOI: http://dx.doi.org/10.1590/S0103-

73312017000400016

12. Sena LM, Tesser CD. Violência obstétrica no Brasil e o ciberativismo de mulheres mães: relato de duas experiências. Interface Comum Saúde Educ.[Internet]. 2017 [citado em 12 ago 2018]; 21(60): 209-20. DOI: https:// doi.org/10.1590/1807-57622015.0896

13. Castro CM, Azevedo AFP. Narrativas sobre parto domiciliar planejado após parto hospitalar. REFACS [Internet] 2018 [citado em 05 ago 2018]; 6(1):53-62. DOI: https://doi.org/10.18554/refacs.v6i1.2794

14. Rodrigues DP, Alves VH, Penna LHG, Pereira AV, Branco MBLR, Silva LA. A peregrinação no período reprodutivo: uma vivência no campo obstétrico. Esc Anna Nery Rev Enf. [Internet]. 2015 [citado em 10 ago 2018]; 19(4):614-20.

https://doi.org/10.5935/1414-

8145.20150082

15. Tesser CD, Knobel R, Andrezzo HFA, Diniz SD. Violência obstétrica e prevenção quaternária: o que é e o que fazer. Rev Bras Med Fam Comunidade. [Internet]. 2015 [citado em 18 ago 2018]; 10(35):1-12. DOI: http://dx.doi.org/10.5712/rbmfc10(35)1013
16. Zanardo GLP, Calderón Uribe M, Nadal AHR, Habigzang LF. Violência obstétrica no Brasil: uma revisão narrativa. Psicol Soc. (Online). [Internet]. 2017 [citado em 02 ago 2018]; 29: e155043. DOI: http://dx.doi.org/10.1590/1807-

0310/2017v29155043

17. Barbosa LC, Fabbro MRC, Machado GPR. Violência obstétrica: revisão integrativa de pesquisas quantitativas. Av Enferm. [Internet]. 2017 [citado em 17 ago 2018]; 35(2):190-207. DOI: $10.15446 / a v . e n f e r m . v 35 n 2.59637$

18. Silva NM, Muniz HP. Vivências de trabalhadores em contexto de precarização: um estudo de caso em serviço de emergência de hospital universitário. Estud Pesqui Psicol. [Internet]. 2011 [citado em 20 ago 2018]; 11(3):821-40. Disponível em: http://pepsic.bvsalud.org/scielo.php?script=sc i_arttext\&pid=S1808-

42812011000300006\&lng=pt\&nrm=iso

19. Mota AES, Gomes L, Bravo MIS, Teixeira M, Marsiglia RMG, Uchôa R. Serviço social e saúde: formação e trabalho profissional. São Paulo: Cortez; 2007. 408p

20. Ribeiro MCSA, Barata RB, Almeida MF, Silva ZP. Perfil sociodemográfico e padrão de utilização de serviços de saúde para usuários e não-usuários do SUS - PNAD 2003. Ciênc Saúde Colet. [Internet]. 2006 [citado em 20 ago 2018]; 11(4):1011-22. Disponível em: https://www.scielosp.org/scielo.php?pid=S14 13-81232006000400022\&script=sci_arttext

21. Brenes AC. História da parturição no Brasil: século XIX. Cad Saúde Pública. [Internet]. 1991 [citado em 01 ago 2018]; 7(2):135-49. Disponível

em: http://www.scielo.br/pdf/csp/v7n2/v7n2a02. pdf

22. Sanfelice CFO, Abbud FSF, Pregnolatto OS, Silva MG, Shimo AKK. Do parto institucionalizado ao parto domiciliar. Rev RENE. [Internet]. 2014 [citado em 18 ago 2018]; 15(2):362-70. DOI: 10.15253/21756783.2014000200022

23. Parto do Princípio. Mulheres em Rede pela Maternidade Ativa. Violência obstétrica: "Parirás com dor". Dossiê elaborado pela Rede Parto do Princípio para a CPMI da Violência Contra as Mulheres [Internet]. 2012 [citado em 15 ago 2018]. Disponível em: https://www.senado.gov.br/comissoes/docu mentos/SSCEPI/DOC\%20VCM\%20367.pdf 24. D’Orsi E, Bruggemann OM, Diniz CSG, Aguiar JM, Gusman CR, Torres JA, et al. Desigualdades sociais e satisfação das mulheres com o atendimento ao parto no Brasil: estudo nacional de base hospitalar. Cad. Saúde Pública. [Internet]. 2014 [citado em 17 jul 2018]; 30(Supl):S154-68. DOI: http://dx.doi.org/10.1590/0102311X00087813 
25. Norman AH, Tesser CD. Obstetrizes e enfermeiras obstetras no Sistema Único de Saúde e na Atenção Primária à Saúde: por uma incorporação sistêmica e progressiva. Rev Bras Med Fam Comunidade. [Internet]. 2015 [citado em 25 ago 2018]; 10(34):1-7. Disponível em: DOI:

http://dx.doi.org/10.5712/rbmfc10(34)1106 26. Organização Mundial da Saúde. Declaração da OMS sobre taxas de cesáreas [Internet]. Genebra: Organização Mundial da Saúde; [2015][citado em 15 ago 2018]. Disponível em http://apps.who.int/iris/bitstream/10665/16 1442/3/WHO_RHR_15.02_por.pdf

27. Barbosa GP, Giffin K, Ângulo-Tuesta A, Gama AS, Chor D, D’Orsi E, et al. Parto cesáreo: quem o deseja? Em quais circunstâncias. Cad Saúde Pública. [Internet]. 2003 [citado em 08 ago 2018]; 19(6):1611-20. Disponível em: http://www.scielo.br/pdf/csp/v19n6/a06v19 n6.pdf

28. Anais da $8^{a}$ Conferência Nacional de Saúde; 1986 Mar 17-21; Brasília, DF [Internet]. Brasília, DF: Centro de Documentação do Ministério da Saúde;1987 [citado em 15 ago 2018]. 430p. Disponível em: http://bvsms.saude.gov.br/bvs/publicacoes/0 219VIIIcns.pdf

\section{CONTRIBUIÇÕES \\ Todas autoras tiveram iguais contribuições.}

\footnotetext{
Como citar este artigo (Vancouver)

Faleiros MCPPN, Oliveira NHD. Como o trabalho precarizado na saúde afeta o modo de nascer: revisão integrativa sobre violência obstétrica. REFACS [Internet]. 2019 [citado em inserir dia, mês e ano de acesso]; 7(3):345-356. Disponível em: inserir link de acesso. DOI: inserir link do DOI.

Como citar este artigo (ABNT)

FALEIROS, M.C.P.P.N.; OLIVEIRA, N.H.D. Como o trabalho precarizado na saúde afeta o modo de nascer: revisão integrativa sobre violência obstétrica. REFACS, Uberaba, MG, v. 7, n. 3, p. 345356, 2019. Disponível em: inserir link de acesso. Acesso em: inserir dia, mês e ano de acesso. DOI: inserir link do DOI.

Como citar este artigo (APA)

Faleiros, MCPPN. \& Oliveira, NHD (2019). Como o trabalho precarizado na saúde afeta o modo de nascer: revisão integrativa sobre violência obstétrica. REFACS, 7(3), 345-356. Recuperado em: inserir dia, mês e ano de acesso de inserir link de acesso. DOI: inserir link do DOI.
} 